Базаров Т.Ю., Кузьмина М.Ю.

\title{
Процессы социальной идентичности в организациях
}

Расширение и усложнение социальной реальности порождает появление новых видов идентичности. Разнообразие организаций и рабочих групп, в которые включены люди, подразумевает особый вид сочиальной идентичности, которая может быть обозначена как профрессиональная, организационная или управленческая. Исследование процессов социальной индентичности в организациях - новая междисциплинарная область, особенно широко представленная в европейской социальной психологии, результатом ее теоретического осмысления стала теория социальной идентичности. В статье выделяются и анализируются зарубежные теоретические разработки и эмпирические исследования в этой области: организационная идентичность и организационная идентифрикация; теория социальной идентичности и лидерство; рабочая мотивация и целеполагание; организационное слияния и различия в организациях.

Ключевые слова: идентичность, организационная идентификация, лидерство, целеполагание, организационные различия и слияние.

Стратегическое управление человеческими ресурсами в 21-ом веке из метафоры превратилось в реальность. Возникли новые горизонты: глобализация, разнообразие форм и методов управления и обучения, инорормационные и кадровые технологии, интеллектуальная и социальная капитализация. Существенно ускорился темп изменений, жизненные циклы становления и развития специалистов и организаций стали короче. Организационные приоритеты неуклонно смещаются в область «человеческого измерения», обозначая в ряду ключевых компетенций организаторские способности, гибкость и быстроту реакции. Соревновательная площадка организаций из сферы производства и продаж неизбежно перемещается в область знаний, отношений и новых идей. Индивидуальность работника, его талант и способности обретают значимость самого исключительного «товара» на глобальном рынке. Что же в этих условиях происходит с людьми и группами? Как они адаптируются и раз- 
виваются в условиях перехода к виртуальным организациям, сопряженным с необходимостью постоянно быть включенными в сетевые структуры? Расширение и усложнение социальной реальности очевидно порождает появление новых видов идентичности. С одной стороны, это выступает как проблема множественности, а нередко и фрагментарности идентичности, с другой стороны - как возможность большей свободы в выборе и самоопределении человека в изменяющемся мире.

Организационная идентификация. Проблематика социальной идентичности является одной из наиболее разрабатываемых в социальной психологии. Особенно широко данная проблема представлена в европейской социальной психологии, и результатом её теоретического осмысления является теория социальной идентичности (ТСИ) (Social Identity Theory (SIT)), разработанная A. Тэшфелом и теория самокатегоризации (ТCK) (Self-Categorization Theory (SCT)), предложенная Дж. Тернером. В настоящее время понятия теории социальной идентичности широко применяются как объяснительные инструменты в различных областях социально-психологического знания. Одним из таких пересечений теории и практики является исследование процессов социальной идентичности в организациях. Эта новая междисциплинарная область имеет большой потенциал для развития обеих направлений - как ТСИ и ТСК, так и организационной психологии и психологии управления персоналом. Об увеличении внимания учёных к данной проблематике свидетельствуют многочисленные публикации; конференции (например, в 2000-м году в Амстердаме), а так же семинары и воркшопы (к примеру летняя психологическая школа, организованная Европейской Ассоциацией Экспериментальной Социальной Психологии в 2002-м году в Германии), посвящённые процессам социальной идентичности в организационном контексте.

Анализ литературы [4, с. 5; 8, с. 15; 18, с. 22], позволяет выделить несколько направлений теоретических разработок и эмпирических исследований в этой области: организационная идентичность и организационная идентификация; ТСИ и лидерство; рабочая мотивация и целеполагание, а также слияния и различия в организациях.

Тэшфел определил социальную идентичность как часть Яконцепции индивида, которая возникает из осознания своего членства в социальной группе вместе с ценностным и эмоциональным значением, придаваемым этому членству [1]. Поскольку организация может быть рассмотрена как социальная группа, она также представляет собой основание для формирования определённого аспекта идентичности. Применение ТСИ в рамках организационной психологии повлекло за собой 
большое количество исследований, связанных с использованием понятия «организационная идентификация» (organizational identification). Как известно, А. Тэшфел разводил понятия «идентификация» как процесс и «идентичность» как продукт этого процесса [1].

Эшфорт и Маел определяют организационную идентификацию исходя из того, что она является специфической формой социальной идентификации. Организационная идентификация подразумевает принадлежность к организации, которая отражается в Я-концепции как членство в социальной группе. Определение индивидом себя в терминах организации обеспечивает частичный ответ на вопрос «Кто Я?» и включает три аспекта: когнитивный (знание о принадлежности к организации), ценностный (наличие позитивных или негативных коннотаций организационного членства) и эмоциональный (принятие организации на основании двух первых показателей). Такое самоопределение влияет на поведение и приводит к действиям, которые конгруэнтны организационной идентичности [4].

Человек идентифицирует себя с группой, когда в процессе принятии решения он оценивает несколько альтернатив в своём выборе в терминах последствий для данной группы [18]. Соответственно, если человек, принимающий решения, идентифицирует себя с организацией, он стремится к выбору такой альтернативы, которая наилучшим образом содействует интересам организации [8].

Исследователи организационной идентификации выделили три основных характеристики этого феномена. Во-первых, организационная идентификация имеет прямое отношение ко всем социальнопсихологическим процессам, происходящим в организациях. Во-вторых, организационная идентификация оказывает сильное влияние на принятие организационных решений. В-третьих, коллективная организационная идентификация поддерживается организационной коммуникацией и зависит от структуры организации [12].

Многие авторы отмечают, что организации обеспечивают сотрудникам множественное групповое членство, поскольку они являются сетями групп (подразделений, команд, отделов и т.д.). Одной из основных гипотез, выдвинутых датским психологом Ван Книппенбергом при исследовании организационной идентификации, является предположение о том, что идентификация с рабочей группой (work-group identification) сильнее, чем организационная идентификация (organizational identification). Автор предлагает ряд обоснований данного утверждения. Вопервых, рабочие группы меньше по размеру, чем организация. Как считает Бревер, люди более склонны идентифицировать себя с относи- 
тельно маленькими группами, поскольку идентификация с большими группами заключает в себе угрозу индивидуальным различиям. Вовторых, индивиды имеют много общего с рабочей группой в плане отношения к работе, общей судьбы и истории. В-третьих, по утверждению Хогга и Абрамса, чем сильнее индивид идентифицирует себя с определённой группой, тем с большей вероятностью он будет думать и действовать в терминах этого группового членства. Из этого следует гипотеза о том, что идентификация с рабочей группой больше коррелирует с организационными установками и поведением, чем идентификация с организацией как целым [21].

Ван Книппенберг экспериментально проверил это предположение, исследовав влияние четырёх переменных, относящихся к организационной идентификации: рабочую мотивацию, включённость в работу, текучесть кадров и удовлетворённость работой. Как выяснилось, организационная идентификация негативно коррелирует с текучестью кадров (что не является неожиданным, поскольку сотрудники, идентифицирующие себя с организацией ценят свой коллектив и организационное членство и стремятся сохранить это и остаться в организации), и позитивно коррелирует с рабочей мотивацией и включённостью в работу и удовлетворённостью работой. Идентификация с рабочей группой имеет более сильную положительную корреляцию с данными переменными, чем идентификация с организацией как целым. Как заключает автор, доказательство этого фракта демонстрирует необходимость системного подхода к организации и рассмотрение различных аспектов организационных установок и поведения, влияющих на организационную идентичность сотрудников [21].

Альберт и Веттен связывают организационную идентификацию с типом организации. Они выделили два типа организаций: идеографические и голографические. Идеографическая организация является фактором наиболее общей формы идентификации сотрудников с объединениями, в которых они работают, что соответствует идентифрикации с рабочей группой, которую исследовали датские психологи. Во втором случае, т.е. в голографической организации сотрудники разделяют общую идентичность, идентифицируя себя с организацией как целым неделимым объектом [21].

Хеннесс и Уэст исследовали связь идентификации в организации с межгрупповыми отношениями. Учёные пришли выводу, что оценочный внутригрупповой фаворитизм позитивно коррелирует с идентификацией с рабочей группой и негативно коррелирует с организационной идентификацией [9]. 
Пэтчен и его коллеги из Мичиганского Университета. выделили три элемента организационной идентификации: а) восприятие характеристик, разделяемых с другими сотрудниками, б) уровень солидарности с организацией и в) поддержка организации. Ключевые положения теории идентификации Пэтчена включали понятия сходства, членства и лояльности. Пэтчен определял сходство как взаимность воспринимаемых совместных целей и интересов других членов организации. Членство описывалось им как уровень связи Я-концепции с организацией, а лояльность - как рабочая поддержка и защита организации [15].

Признание различными исследователями важности организационной идентификации привело к изобретению различных инструментов для её измерения. Автором одного из первых таких инструментов был Ченей, который в 1982 году на основании теории Пэтчена разработал опросник (Organizational Identification Questionnaire (OIQ)) - самый популярный и эффрективный инструмент для диагностики организационной идентификации в настоящее время [8]. Как считает Ченей, организационная идентификация относится к широкому спектру организационных феноменов, включающих организационное поведение, индивидуальное и групповое принятие решений, рабочие установки, мотивацию, удовлетворённость работой, достижение целей, ролевой конфликт, взаимодействие сотрудников, текучесть персонала и организационную эффективность [8].

Несколько лет назад Джонсоном и Неймергом была повторно проанализирована структура данного опросника. В результате применения фракторного анализа исследователи выделили несколько компонентов организационной идентификации, отличных от трёх - лояльности, сходства и членства, предложенных изначально Пэтченом. Первый компонент был описан авторами в терминах атрибутов организационной работы, включающих рабочий контекст (характеристики организационной среды) и психологические характеристики работы (такие как имидж организации, её ценности и собственно организационную идентифрикацию). Второй компонент сохранил своё прежнее название - организационная лояльность, и включал в себя преданность, верность, заботу и уважение. Эти характеристики относятся к компонентам первого порядка. Компоненты второго порядка, которые является обобщением первичных составляющих организационной идентификации, включает два кластера: имидж/ идентичность и миссию/ цель [12]. Как мы видим, организационная идентификация определяется в терминах организационной культуры, а именно такими её характеристиками как ценности, имидж, миссия и цель. Представляется очевидным, что сила организационной 
идентификации зависит от степени принятия корпоративной культуры и её соответствия индивидуальным особенностям сотрудников и руководителей. Как отмечает С.А. Липатов, необходимо исследование социальных фракторов, оказывающих существенное влияние на организационную преданность и идентификацию, в частности, национальной и организационных культур [2].

Аллен и Майер рассматривают идентификацию как составляющую более общего, по их мнению, психологического конструкта - преданности организации, который отражает силу связи, существующей в представлении человека, между ним и конкретной организацией, в которой он работает. Наряду с лояльностью и вовлечённостью, преданность включает идентификацию как твёрдую убеждённость в корпоративных ценностях и принятие целей данной организации (см. 2).

Теория социальной идентичности и лидерство. Существуют несколько подходов к анализу лидерства с позиций ТСИ. Одним из наиболее удачных вариантов интерпретации данной проблемы, на наш взгляд, является работа австралийского учёного Майкла Хогга «Лидерская теория социальной идентичности» (ЛТСИ) («А Social Identity Theory of Leadership») [10]. Если многие исследования организационной идентификации были выполнены в рамках организационной психологии, то Хогг делает акцент не на организационном контексте, а на социальнопсихологической природе лидерства. При этом его работа даёт основания для анализа организационного лидерства с точки зрения психологии социального познания.

До Хогга многие учёные (Лорд, Фоти, де Вадер, Нье и др.) обращались к проблематике лидерства с позиций психологии социального познания. Это направление получило название Лидерской Теории Категоризации (Leadership Categorization Theory), которая утверждает, что люди имеют предубеждения по поводу поведения лидеров. Эти предубеждения представляют собой когнитивные схемы типов, или категорий лидеров. Когда кто-то категоризируется на основании своего поведения как лидер, приходит в действие релевантная схема лидерства для генерации дальнейших предположений о его поведении. Таким образом, хорошие лидеры - это те, которые имеют атрибуты категории лидера, отвечающие требованиям ситуации [13]. Данная теория рассматривает лидерские категории как номинальные, а лидерство - как продукт индивидуальной переработки информации. В реальной жизни не существует социальной группы, которая состояла бы только из лидеров, так что это лишь когнитивное группирование характеристик. 
Майкл Хогг рассматривает лидерство как групповой процесс, порождаемый социальной категоризацией и эффектами, связанными с социальной идентичностью. Анализируя исследования лидерства, автор отмечает, что большинство современных подходов делают акцент: а) на индивидуальных когнитивных процессах, которые обеспечивают категоризацию индивидов как лидеров и б) на индивидуальных харизматических качествах, необходимых «преобразующему» лидеру. Первый аспект ближе «европейской» социально-психологической традиции. Второй основывается на «индивидуалистическом» американском подходе, реализованном в традиции теории «Нового Лидерства» (New Leadership) (Басс, Аволио и др.), в рамках которой утверждается, что эфрективные лидеры должны быть инновационными, ориентированными на изменения, способными разделять и поддерживать видение и миссию организации [10]. Хогг как представитель австралийской «третьей силы» предлагает интегративную теорию лидерства, считая необходимым учитывать социальный фактор, имея в виду как групповое членство, так и большие социальные системы... Как отмечает Хогг, на динамику лидерства существенно влияют процессы социального познания, связанные с групповым членством, а именно такие фракторы как: 1) прототипичность, 2) социальная аттракция и 3) атрибуция и переработка информации.

В теории самокатегоризации когнитивный аспект социальной идентичности определяется в терминах причин и следствий социальной категоризации себя и других и разделения социального мира на ингруппы и аутгруппы, которые когнитивно представлены как прототипы. Ингрупповой прототип конструируется под влиянием социального контекста и состоит из набора атрибутов, которые определяют и приписывают установки, чувства и поведение, характеризующие членов группы и отличающие данную группу от других групп [10]. Прототип как способ хранения социальной информации часто определяется в когнитивистской традиции как «лучший пример данной категории» [1]. Таким образом, ингрупповой прототип отражает обобщённый образ типичного представителя данной группы. Прототипичность связана с феноменом деперсонализации, поскольку она подразумевает восприятие других не как уникальных индивидов, а с точки зрения групповых норм. Как отмечает Хогг, члены ингруппы обладают различной степенью прототипичности, т.е. близости к ингрупповому прототипу. Прототипичность представляет собой основание для влияния, и в новых группах наиболее прототипичный член является потенциальным претендентом на роль лидера. Мера влияния лидера на последователей зависит также от степени согласованности ингруппового прототипа и от уровня субъективной неопреде- 
лённости членов группы. Известно, что человек стремится к поддержанию позитивной идентичности и к редукции неопределённости. В этом случае он имеет тенденцию идентифицировать себя с высокостатусными группами и организациями и готовность следовать за прототипичным лидером [10].

Ещё одно основание для влияния в группе - это процесс социальной аттракции. Прототипичные члены группы являются более социально привлекательными, чем не прототипичные, и их идеи принимаются другими с большей готовностью, чем идеи других.

Третий фактор, влияющий на восприятие лидерства в группе - это атрибутивные процессы, призванные, как известно, придавать смысл поведению других. Члены группы склонны конструировать харизматическую личность и приписывать лидерские качества человеку, а не прототипичности его позиции. Это поддерживает основанную на статусе структурную диффреренциацию внутри группы между лидером и последователями. По результатам исследований, сотрудники организаций более склонны к диспозициональной атрибуции, т.е. к приписыванию причин поведения личности (в данном случае личности лидера), в условиях кризиса и организационных изменений [14]. В результате экспериментальной проверки своих предположений Хогг пришёл к следующим выводам: а) групповая идентификация, социальная аттракция и эффективность лидера, основанная на его воспринимаемой компетентности, увеличиваются с ростом групповой сплочённости; б) конгруэнтность лидерской схемы становится менее влиятельной, а групповая прототипичность - более влиятельной детерминантой поддержки лидера его последователями с высоким уровнем идентификации в более сплочённых группах. На основании этих заключений автор рекомендует лидерам сплочённых групп обращать внимание на то, насколько прототипичны они для того, чтобы удерживать власть, а лидерам менее сплочённых групп - на умение сочетать задачи и схемы, специфичные для данной ситуации

Итак, прототипичность и социальная аттракции в совокупности с атрибутивными процессами и процессами переработки информации способствуют переходу от воспринимаемого влияния к активному лидерству. Хогг проводит различие между лидерством как влиянием и властью как принуждением. Прототипичные лидеры, олицетворяя групповые нормы, имеют референтную власть, или власть позиции и не нуждаются в применении личной власти. Поскольку прототипичность связана с сильной ингрупповой идентификацией, и между таким лидером и его последователями существует эмпатическая связь, любая форма не- 
гативного поведения лидера, направленного против ингруппы, направлена и против себя [10].

Теория Лидерства Хогга описывает процессы социальной идентичности в различных фрормах лидерства: стихийном (например, в краткосрочных лабораторных группах) и установленном (в организациях), в малых (команды) и больших группах (нации).

Рабочая мотивация и целеполагание. Один из центральных вопросов в исследованиях организационного поведения - что мотивирует индивидов прилагать усилия на работе. Этот вопрос имеет особое отношение к поведению, которое содействует группе или организации. Вегге и Хаслам предприняли попытку интегрировать положения двух теорий - теории целеполагания и теории социальной идентичности [22]. Это позволило авторам утверждать, что существует некоторая конгруэнтность в природе активации целей и самокатегоризации. Цели выполняют функцию линзы, концентрирующей энергию Я и, таким образом, влияют на индивидуальное поведение. Цели, так же как и «Я», могут быть определены в индивидуальных и групповых терминах. Индивидуальные цели интернализируются как аспекты личностного «Я» и способствуют удовлетворению интересов индивида; групповые цели обращены к социальному «Я» и достижению результата для группы в целом.

Проводя параллель между целями и идентичностью, исследователи утверждают, что в процессе постановки индивидуальных целей актуализируется личностная идентичность, тогда как при групповом целеполагании становится более «выпуклой» социальная идентичность. Когда процесс целеполагания в организации связан с постановкой целей, имеющих отношение к организационному развитию, актуализируется организационная идентичность. Как считают Вегге и Хаслам, процесс группового целеполагания наиболее эффективен, когда обсуждение в рабочей группе или команде проводится в партиципативной форме [22]. Партиципативная культура (от англ. participate - участвовать) подразумевает решение организационных проблем через открытое взаимодействие и всесторонние обсуждения, причём руководитель действует как катализатор группового сотрудничества [3]. Совместный поиск целей сотрудниками и стремление к их достижению необходимы организации для развития креативности и способности к изменениям и росту. При этом безусловной ценностью для организации и условием её прогресса остаётся индивидуальное харизматическое лидерство, но его основным механизмом является не авторитарная установка «я сам», а коллегиальная «давайте сделаем это вместе». 
Основываясь на эмпирических исследованиях целеполагания в организации, авторы пришли к выводу, что специфические и сложные цели приводят к более высокой индивидуальной продуктивности, чем простые и неспецифические цели. Сложные и специфические цели мотивируют сотрудников на то, что они: а) прилагают больше усилий во время выполнения задачи, б) продолжают работать над заданием до тех пор, пока не достигнут результата, в) направляют свои действия и внимание на поведение и результаты, релевантные достижению цели, г) используют или развивают соответствующие стратегии и планы выполнения задания [22].

Различия в организации и организационные слияния. Одним из важных вопросов ТСИ является проблема сходства и различия индивидов. Как утверждает Бревер, люди стремятся к оптимальным различиям, «золотой середине», чтобы сохранить в равновесии потребность включаться в группу (включённость) и индивидуальные различия, желание быть отличным от других (исключительность) [5]. Как показывает ряд исследований, чем больше люди сходны с группой, тем более они склонны идентифицировать себя с ней, поскольку идентификация основана на категоризации себя как подобного другим внутри категории. Исследованию этих аспектов организационной жизни - а сотрудники организаций как члены группы также склонны к категоризации себя как сходных или отличных от других, посвящены работы Ван Книппенберга и его коллег $[19,20]$. Одна из них касается идентичности и организационных различий (organizational diversity), другая - слияния организаций (organizational merger) и его эфрфектов.

Как отмечают Ван Книппенберг и Хаслам, различие является фактом организационной жизни, поскольку большинство рабочих групп состоят из людей, отличающихся по своим демографическим характеристикам, установкам, нормам, ценностям, знаниям и т.д., а организации отличаются друг от друга по своей структуре, целям, культуре и др. [19]. Обращаясь к ТСИ, исследователи определяют различие как важный аспект содержания идентичности. Любопытно, что в основе этого факта лежат представления членов группы о том, что для них является объединяющим, что делает их группу «хорошей группой»- уникальные характеристики каждого или нечто общее, присутствующее у всех. Члены группы, воспринимающие её как гетерогенную, более склонны идентифицировать себя с ней, быть более преданными и удовлетворёнными своим групповым членством. Джен, Норскрафт и Ниал выделили несколько типов различий: информационное, различие социальных категорий и ценностное различие. Они обнаружили, что информационное 
различие позитивно коррелирует с эфффективностью работы группы, тогда как два последних вида различий имеют с ней негативную корреляцию [11].

Исследуя организационные слияния, т.е. объединение организаций в одну более крупную, Даан ван Книппенберг и Барбара ван Книппенберг пришли к выводу, что слияния оказывают большое психологическое влияние на людей, включённых в этот процесс [20]. Анализируя процессы социальной идентичности в организациях до и после слияния, учёные обнаружили, что организационная идентификация зависит от чувства непрерывности, целостности, которое в свою очередь определяется доминантностью организации по отношению к её партнёру по слиянию. С точки зрения ТСИ и ТСК слияние может быть определено как фрормальная рекатегоризация двух социальные групп как одной новой группы, что приводит к изменениям в организационной идентичности. Сотрудники, став членами новой группы, начинают заново адаптироваться к ней, что обуславливает возникновение чувства прерывания, нарушения целостности, особенно если одна из организаций является доминирующей. Как показывает практика, большинство организационных слияний происходят как поглощения, когда одна из организаций является большей по размеру и более влиятельной, чем другая. В таком случае члены доминирующей организации испытывают гораздо меньше дискомфорта от произошедших изменений, в то время как члены подчинённой организации воспринимают этот фракт как изменение группового членства. Можно считать, что ключевым фрактором в определении организационной идентификации после слияния является организационная доминантность. Авторы этого исследования разводят понятия доминантности и статуса. Несмотря на то, что ТСИ использует понятие «статус» и рассматривает взаимоотношения между группами в терминах статусных позиций, а не доминантности (как утверждает ТСИ, высокостатусные группы обеспечивают более высокий уровень идентификации), авторы настаивают на использовании термина «доминантность». Это обусловлено тем, что часто в слияниях организация, которая является, если можно так выразиться, «субъектом» слияния, оказывается более высокостатусной, чем доминантная. В этом смысле доминантность ближе понятию «власть», хотя и оно не совсем точно определяет суть данного различия [20].

Относительно понятия «доминантность» ТСИ не избежала участи «быть использованной», и результатом её применения стали исследования в области социальной доминантности. Это как раз пример того случая, когда один из субъектов слияния является высокостатусным 
(ТСИ), но не доминирующим. Одна из новых западных социальнопсихологических теорий, объединивших в себе идеи многих научных предшественников - это Теория Социальной Доминантности (ТCД) (Social Dominance Theory), разработанная американскими учёными Фелисией Пратто и Джимом Сиданиусом [16, 17]. Основываясь на положениях теории авторитарной личности; двухценностной теории политического поведения Рокича; теории групповых позиций Блюмера; теории марксизма и неоклассической элитарности; результатах исследований политических установок и общественного мнения, и, наконец, как мы уже отметили, теории социальной идентичности, эта синтетическая концепция, по словам её авторов, является попыткой соединить миры индивидуальной личности и социальной структуры. Как утверждает эта теория, все человеческие общества имеют тенденцию структурироваться как системы социальных иерархий, основанных на группах. Эти иерархические социальные структуры состоят из доминирующих групп «на вершине» и одной или нескольких подчинённых групп «внизу». Авторы разводят понятия индивидуальной и групповой социальной иерархии. Под первой они понимают обладание властью, престижем и богатством на основании личностных характеристик, таких как способность к лидерству, высокий интеллект, артистичность, политический или научный талант, достижения и др. Социальная иерархия групп относится к социальной власти, статусу и привилегиям, которыми обладает индивид через приписывание себе членства в определённых социально конструированных группах, таких как раса, религия, клан, племя, этническая группы, социальный класс и т.д. Групповая социальная иерархия включает три стратификационные системы: возрастную, гендерную и систему произвольно-образуемых групп. Общее стремление поддерживать групповую социальную иерархию и доминировать над «худшими» группами авторы называют ориентацией на социальную доминантность (ОСД). ОСД относится к базовому желанию иметь собственную ингруппу, которая является лучше, преимущественнее и доминантнее по отношению к релевантной аутгруппе. На ОСД влияют 4 фактора: 1) членство и идентификация с произвольной, сильно выдающейся и иерархически организованной группой; 2) факторы социализации (уровень образования, вера и др.); 3) врождённые особенности темперамента (например, считается, что чем больше способность к эмпатии, тем ниже уровень ОСД); 4) гендер (у мужчин гораздо больший уровень ОСД, чем у женщин) [17]. Авторы разработали шкалу, измеряющую уровень социальной доминантности, которая включает 20 пунктов (например, «некоторые группы людей более достойны, чем другие» или «победа важнее процесса игры»); они 
утверждают, что ОСД существенно отличается от личностной доминантности, которую, например, измеряет одна из шкал опросника СРI.

В рамках ТСД было проведено большое количество исследований, но поскольку нас интересует проблематика социальной идентичности, мы приведём лишь некоторые результаты. Пратто и Сиданиус исследовали взаимодействие ингрупповой идентификации, ОСД и «дифференциального межгруппового социального положения» (differential intergroup social allocation), операционализировав последнее в трёх индексах: дифференциальная межгрупповая оценка, социальная дистанция и групповая кооперация. Эксперименты, проведённые в традиционной минимальной групповой парадигме, показали, что существует статистически значимая корреляция между ингрупповой идентификацией, ОСД и социальной дистанцией (те, кто сильно идентифицируют себя с ингруппой и имеют высокой уровень ОСД, чувствуют большую социальную дистанцию по отношению к аутгруппе.) Дифференциальная межгрупповая оценка представляла собой меру компетентности ингруппы и аутгруппы. Выяснилось, что чем выше уровень ингрупповой идентификации, тем более ингруппы рассматриваются субъектами как относительно компетентные, и чем выше уровень личной самооценки, тем больше различие в воспринимаемой компетентности между ингруппой и аутгруппой, и тем меньше желание субъектов кооперировать с аутгруппой [17]. С нашей точки зрения, социальные организации также могут быть рассмотрены как групповые социальные иерархии, которые в постоянно изменяющейся агрессивной внешней среде имеют тенденцию конкурировать, доминировать и активно подавлять друг друга. Тогда стремление к членству в той или иной организации, особенно к управленческим позициям, частично включает в себя ориентацию на социальную доминантность.

\section{$* * *$}

Как мы видим, Теория Социальной Идентичности безжалостно эксплуатируется различными учёными и обладает большим потенциалом в плане теоретических объяснений и оснований для прикладных исследований в области психологии организаций и управления персоналом. Кроме этого, по мнению Р. Брауна, современного британского исследователя, существует несколько областей, которые являются наиболее перспективными в плане дальнейшего развития этой теории: само понятие идентичности; введение в теорию аффрективного компонента; одновременное управление множественными идентичностями; и включение 
имплицитных процессов в анализ идентификации и ее эфрфектов [7]. Как считает автор, с точки зрения расширения понятия идентичности необходимо уделить большее внимание разнообразию групп, которые могут лежать в основе социальной идентичности. В настоящее время ТСИ не проводит различия между разными типами групп. Все группы - являются ли они малыми объединениями или большими масштабными общественными категориями - относительно действия процессов социальной идентичности мыслятся как психологические эквиваленты для своих членов. Но, как показывает ряд исследований, различные группы могут способствовать абсолютно разным функциям идентичности [6].

Таким образом, разнообразие организаций и рабочих групп, в которые включены люди, подразумевает особый вид социальной идентичности, которая может быть обозначена как профессиональная, организационная или управленческая (если речь идёт о руководителях), и данное групповое членство обеспечивает разнообразие функций идентичности, исследование которых позволит значительно расширить как само понятие «идентичность» так и область его применения.

\section{Лumepamypa}

1. Андреева Г.М. Психология социального познания. Аспект Пресс, М., 2000.

2. Липатов С.А. Преданность организации как проблема организационной психологии // Ежегодник российского психологического сообщества. Психология и её приложения, т.9, вып.3, М., 2002.

3. Управление персоналом под ред. Базарова Т.Ю., Ерёмина Б.Л., М., ЮНИТИ, 2001.

4. Ashforth, B. E., \& Mael, F. Social identity theory and the organization. //Academy of Management Review, 1989, 14.

5. Brewer, M. B. The social self: On being the same and different at the same time.// Personality and Social Psychology Bulletin, 1991, 17.

6. Brown R, Williams J.A. Group Identification: the same thing to all people? // Human Relations, 1884, 37.

7. Brown R. Social Identity Theory: past achievements, current problems and future challengers.// European Journal of Social Psychology, 30, Agenda 2000.

8. Cheney G., \& Tompkins, P. K. Coming to terms with organizational identification and commitment.// Central States Speech Journal, 1987, 38.

9. Hennessy J., West M. Intergroup behavior in organizations // Small Group Research, Jun1999, Vol. 30, Issue 3. 
10.Hogg M. A. Social Identity Theory of Leadership. // Personality \& Social Psychology Review , 2001, Vol. 5, Issue 3.

11.Jehn K.A., Northcraft G.B., Neale M.A. Why differences make a difference: A field study of diversity, conflict and performance in workgroups. // Administrative Science Quarterly, 44.

12.Johnson W., Johnson A., Heimerg F. A primary- and second-order component analysis of the organizational identification questionnaire.// Educational \& Psychological Measurement, Feb1999, Vol. 59 Issue 1.

13.Lord, R. G., Foti, R. J., \& DeVader, C. L. (1984). A test of leadership categorization theory: Internal structure, information processing, and leadership perceptions. Organizational Behavior and Human Performance, 34, 343-378.

14.Meindl, J. R., Ehrlich, S. B., \& Dukerich, J. M. The romance of leadership.// Administrative Science Quarterly, 1985, 30.

15.Patchen, M. Participation, achievement, and involvement on the job., Englewood Cliffs, NJ: Prentice Hall, 1970.

16.Sidanius J., Pratto F. Social dominance. An Intergroup Theory of Social Hierarchy and Oppression. Cambridge University Press,1999.

17.Sidanius, J.; Pratto, F. In-group identification, social dominance orientation, and differential intergroup social allocation. // Journal of Social Psychology, Apr1994, Vol. 134 Issue 2.

18.Simon, H. A. Administrative behavior: A study of decision-making processes in administrative organization (3rd ed.), New York: Free Press, 1976.

19.Van Knippenberg D., Haslam A. Diversity and Identity. (to appear in Van Knippenberg D., Haslam A., Platow M., Ellemers N. Social identity at work: developing theory for organizational practice. New York: Taylor \& Francis).

20.Van Knippenberg D., Van Knippenberg B. Organizational Identification after a Merger: A Social Identity Perspective. British Journal of Social Psychology, in press.

21.Van Knippenberg D.; van Schie, Els C. M. Foci and correlates of organizational identification.// Journal of Occupational \& Organizational Psychology, Jun2000, Vol. 73 Issue 2.

22.Wegge J., Haslam S. Group goal setting, social identity and selfcategorization: engaging the collective self to enhance group performance and organizational outcomes. Manuscript under review. 